\title{
Correspondence
}

\section{'Bridges over Troubled Waters'}

\section{DEAR SIRS}

'Curing the sick is not enough, one must cure them with the method accepted by the community' re Johann Joseph Gassner $(1727-1779)^{1}$.

I warmly welcome the letter of Dr John Steiner and the paper 'Cut Price Adolescent Units that Meet all Needs, and None' by Dr Peter Wells in the September 1986 Bulletin. Their comments about the HAS document, Bridges Over Troubled Waters, have opened the way for frank discussion about the Report and its implications for the service.

I must confess to being unable to see the political naivety of the document, commented on by Wells; it was its clinical naivety which struck me most. Whilst I agree with his view that a single adolescent unit doing everything for all adolescent problems is unrealistic, I do not agree with him as to the kind of differentiation that needs to be made.

I was particularly glad of Steiner's observations on the bias of the document. Being Chairman of the Association for Psycho-Analytical Psychotherapy, his remarks, however, may well be taken by the non-clinical part of the establishment as a biased opinion, even though he has assured us that he was not "plugging a line for psychotherapy"; and his views seen as one point of view regarding the treatment of adolescent disturbance as opposed to another expressed in the HAS Report, thus giving the latter an undeserved respectability and credibility.

I am an adolescent psychiatrist, eclectic in my training and practice, who has worked intensively with every type of adolescent problem for the last 18 years. My own unhappy experiences of a Review of the Unit I had been in charge of for 10 years, will I believe, provide ample evidence for the bias against psychodynamics that is around.

We described our Unit as "psychodynamically orientated" which has sometimes made it possible to contain the "uncontainable", manage the "unmanageable", and treat the "untreatable". We have treated together every type of adolescent problem, mixing psychotics with non-psychotics of different types. Wells' vivid description of the "lynchmob culture" that arises when one tries to mix psychotics with other types of disturbances was all too familiar to us. We took the dynamics of such situations further and helped the non-psychotic youngsters to recognise, reach and own their inner feelings of madness. This resulted in rich gains in their understanding of themselves and in a dramatic increase of their capacity to accept the psychotics. It also enabled us to differentiate clearly between the psychotic and the pseudo-psychotic.
We treated in-patients on compulsory detention orders, glue-sniffers, drug abusers (not addicts), epileptics, elective mutes, sexual perverts, obsessional neuroses, anorexics, youngsters with physical handicaps and delinquents, in addition to psychotics and conduct and emotional disorders. We operated as a second or third tier treatment unit, dealing with the most disturbed youngsters in the Region, and had a $70 \%$ rate of successful treatment outcome. It was because of our strong psychodynamic orientation that we were able to do this. It was a Unit in which staff stayed.

The Review Team which visited the Unit made a signifcant observation: "Interpretative psychodynamic therapy is applicable to a certain range of adolescent problems. . . as this is the major mode of therapy at Brookside, attempts have been made to restrict admission to suitable young persons". Similar observations were scattered in eight different places throughout the 'Review' report. A carefully worked out evaluation of our work was not looked at, and strong recommendations were made for the immediate closure of the Unit, dispersal of patients and staff, and the removal of the Consultant Psychiatrist and Medical Director from his position. I felt we had been politically unwise in calling ourselves "psychodynamically orientated".

An earlier JCHPT report on the work of the unit which stated "a wide range of problems is dealt with... the Consultant is an analytically orientated psychiatrist, particularly well-trained in this type of work. He appears to be providing an excellent experience for the trainee in adolescent psychiatry", I felt had done us a dis-service.

My own view of the recommendations of the HAS Report regarding the role of psychiatry and psychiatrists is that they are indefensible. The greatest 'value' of the report is its self-contradictory nature, which allows psychiatrists in charge of units to do anything they want. Those who have had a comprehensive eclectic training ranging from formal psychiatry to psychodynamics will be free to run units which are flexible and wide ranging in the work they do, lavishly recommended in the report-paras 2.1.6, 6.11, 7.1.6, 7.11.4, whilst those who are more limited in their training can point to para. 3.1.1, a paragraph which makes the most clear and definitive statements of the psychiatrist's role, and feel justified in running units with strictly limited and rigid policies, taking clinical responsibility only for youngsters with "identifiable psychiatric disorders".

However, mere criticism of the HAS Report and the Steering Committee is not enough. There are bigger issues. How and why has this situation crept up on us? How is it that an establishment of high intellectual ability and a noble tradition does not seem to see that true eclecticism would include psycho-dynamics, as well as other forms of treatment; that even the differential diagnosis and appropriate treatment of identifiable psychiatric disorders is not 
possible without a knowledge of psychodynamics? Why is psychodynamics, so much sought after in the psychiatric world, eschewed in adolescent psychiatry where it is needed most? What are the implications of this report for training and the future of adolescent psychiatry?

Whatever the answers to these questions, I believe that the HAS Report on the role of psychiatry and psychiatrists is anti-developmental and anti-progressive. The situation today is reminiscent of an era over two centuries ago, when Johann Joseph Gassner, Honorary Physician to the Court of Prince Bishop of Regensburg, was removed from his position. He was widely acclaimed for success in his treatment methods, and equally known for his honesty and sincerity. He was using the early psychodynamic techniques and had lost favour with the authorities. ${ }^{1}$

Finally, I would like to respond to the appeal of Professor Goldberg and others in the February 1986 Bulletin. Management acted on the recommendations of the Report before studying it themselves. I wrote a detailed response to the 'Review' report producing documented evidence to show it to be a misrepresentation. Independent responses were also written by the clinical staff and the nursing staff of the Unit. These responses were sent to the Region, relevant organisations and individuals. Several spontaneous letters to the Region from ex-staff of the Unit and psychiatric colleagues, who had worked closely with the Unit and knew it well, contradicted the observations and recommendations of the 'Review' report.

After many months, the Region decided to re-open. I remain its Consultant Psychiatrist and Medical Director. There is hope.

Brookside Young People's Unit Goodmayes, Essex

\section{K. S. Perinpanayagam}

REFERENCE

'ELLENBERGER, HeNRI F. (1970) The Discovery of the Unconscious, the History and Evolution of Dynamic Psychiatry. Harmondsworth: Allen Lane/The Penguin Press. Pp 53-57.

\section{DeAr Sirs}

Dr Wells and Dr Steiner (Bulletin, September 1986, 10, 231-232 and 246) offer criticisms of this report which I would like to defend. Our survey revealed that, with some striking exceptions, services for disturbed adolescents in England and Wales are uneven, piecemeal and palpably deficient in meeting the needs of many young people. The direct contribution which psychiatrists can make is an important element of the overall picture. It was disappointing to find that specialist adolescent psychiatric services were often isolated, unduly selective and failing to provide advice and support to adjacent organisations and disciplines. The 'elsewhere', to which Dr Wells' unit for instance directs psychotic youngsters, is unfortunately not universally guaranteed to provide appropriate treatment and support and it is good to see that Mersey RHA are taking steps to fill the gap.
Dr Steiner and Dr Perinpanayagam (above) regard the Report as biased because it fails to advocate a psychoanalytic approach to the problems of disturbed adolescents. The omission was deliberate: the Steering Committee believed that promotion of any particular philosophy of management could only lead to unproductive internecine argument which would obscure the real needs. Instead, as Dr Perinpanayagam acknowledges, the Report repeatedly advocates eclectic services which offer a range of therapeutic approaches. He must realise too that the intention of our recommendation that psychiatrists should have a primary responsibility for all those suffering from identifiable psychiatric disorder was to encourage greater "inclusivity" and to discourage the exclusion of such young people so frequently found today.

[Because Dr Perinpanayagam's letter refers to earlier criticism of the Health Advisory Service, readers of the Bulletin may be led to believe that the Review of the Brookside Young People's Unit which he describes was conducted by HAS. It was not].

Dr Steiner is critical of our failure to analyse the antecedent causes of adolescent disturbance. Such a task was outside the remit of a group striving to plan more rational services. But the Report calls specifically for research into child and family development, for longitudinal studies and for evaluation of preventive programmes.

Bridges Over Troubled Waters provides a clear description of massive unmet need and proposes an organisational and professional framework by which, for the first time, the needs of disturbed adolescents could be met comprehensively. The consideration which the College is giving to the recommendations is part of a national reappraisal of adolescent services which the Report has stimulated. An environment now exists in which psychiatrists can play a major role in adolescent service development and make well-reasoned bids for resources. Time will be wasted if it is devoted to partisan issues or defence of the indefensible current position.

NHS Health Advisory Service
Brighton Road

PETER Horrocks

Sutton, Surrey

\section{Psychotic adolescents}

\section{DeAr Sirs}

We would like to express our concern about one particular issue raised by Peter Wells, Consultant Adolescent Psychiatrist, Macclesfield Health Authority, Young People's Unit, Macclesfield (Bulletin, September 1986, 10, 231-232).

It would seem that most of his argument stems from the premise that psychotic adolescents cannot be managed with those having emotional or conduct disorders. We are not clear on what grounds he finds himself able to make this statement. Our own experience-admittedly limited by virtue of the small numbers-would indicate that psychotic young people are well tolerated by their peer 